\title{
Effect of Surface Texture on Tensile Shear Strength of 1060AI-PET Welding Joints
}

\author{
Jia Liu ${ }^{1,2,3^{*}}$, Yuchi Dai ${ }^{1,2,3}$, Yan Shi ${ }^{1,2,3}$, Wenfu Cui ${ }^{1,2,3}$ and Tao Jiang ${ }^{1,2,3}$
}

\begin{abstract}
Joining metal to plastic can lighten weight of products to reduce energy consumption. However, it is difficult to achieve high-strength welding between metal and plastic. To address this problem, the methods of surface texture pretreatment and laser irradiation welding was proposed to achieve the high-strength connection of metal and plastic. In this study, with different parameters of laser power and texture morphology, 1060 Al with surface texture treatment was joined to polyethylene terephthalate (PET) by laser irradiation welding from metal side. Study showed that as the laser power increased, the tensile shear strength of joints increased first, and decreased thereafter. Tensile shear tests demonstrated that the mechanical force of joint was strengthened contributed to mechanical anchorage formed by surface texture. The depth-width ratio of the texture grooves affected the tensile shear process of the joint. According to the result of temperature simulation, the existence of texture grooves reduced the heat transfer efficiency, and the heat dissipation at interface was also impeded in course of laser welding. Finally, the maximum tensile strength of 1060AI-PET joint reached 48.4 MPa, which was close to the strength of PET matrix. The bonding mechanism of the 1060AI-PET joints was composed of mechanical bonding and chemical bonding. This study proposes an effective method to join metal to plastic which achieved high-strength connection between metal and plastic.
\end{abstract}

Keywords: 1060Al-PET, Surface texture, Tensile shear strength, Depth/width ratio, Mechanical anchoring effect

\section{Introduction}

Vigorous impetus is injected into the modern industry because of the application of new materials and new energy. Recently, the connection between metal and polymer materials has broad prospects in lightweight application. Polymer materials (polymers) extensively utilized in many industries to achieve weight reduction, electrical insulation and good corrosion resistance in manufactured components $[1,2]$. In particular, PET, one of a polymer, is applied to digital products, automobiles as structural materials by virtue of its lightweight and remarkable mechanical properties [3-5]. Moreover, fiber reinforced thermoplastic composites are a new

\footnotetext{
*Correspondence: liujia@cust.edu.cn

${ }^{1}$ School of Electromechanical Engineering, Changchun University

of Science and Technology, Changchun 130022, China

Full list of author information is available at the end of the article
}

lightweight structural material. It is widely used in new energy equipment, aerospace and automobile manufacturing owing to its high specific strength, good corrosion resistance and good fatigue resistance $[6,7]$. So the research on the connection of fiber reinforced thermoplastic composites and metals has superior engineering application value. Due to the main part of fiber reinforced thermoplastic composites is constructed of thermoplastic resin. When it is connected to metal, the contact surface can actually be considered as a connection between metal and plastic. Metals are the most important engineering material utilized in industrial production. Especially, aluminum alloys are widely used in automotive industry and aerospace $[8,9]$, because of its relative low density, excellent corrosion resistance, relative high strength and good formability [10-12]. The connection of dissimilar materials just like metal and plastic has the advantage of achieving better structural 
performance. Therefore, most engineering structures are made of metal and plastic. However, the direction joining of plastic to metal materials is difficult because of their fundamentally different chemical and physical properties.

The approaches to the direct joining of plastic to metal have been investigated recently, such as friction spot welding (FSW) and laser joining. Toshiya Okada [13] and Peng Jun [14] conducted FSW on Al alloy and plastic. They achieved the joint of $\mathrm{Al}$ alloy to $\mathrm{ABS}$ and PET successfully. But the FSW technique also has its own drawbacks. For example, FSW demands the stirwelding head with high stiffness and the surface of the material with high quality. Therefore, the technical application requires high cost. Laser welding is another approach to join metal and plastic materials. To obtain the metals-plastics lap joints with good performance, researchers have developed laser direct joining process of metal and plastic [15-18]. In this process, a laser beam is simply irradiated from metal side. This tech has improved its prospects by producing good performance joints between plastic and different metallic materials such as stainless steel, $\mathrm{Mg}$ alloys and $\mathrm{Al}$ alloys. But the joints of metals-plastics cannot be accompanied by high tensile shear load.

To overcome this problem, surface pre-treated tech is applied to the metals-plastics welding. Researchers have proposed many methods to treat the surfaces of metal parts, including grit blasting, shot peening and chemical treatment. But these methods have common drawbacks such as lack of flexibility and environmental pollution. On the contrary, the laser surface treatment can avoid these problems. Grujicic reviewed previous different approaches for polymer-metal joining, and pointed out that the one based on micro-scale mechanical interlocking is the most promising method [19]. Heckert and Zaeh [20] reported laser processed surface structures can be used for thermal joining of aluminum with fiber reinforced thermoplastics. Jung et al. [21, 22] conducted laser welding of carbon fiber reinforced plastic (CFRTP) with different metal materials. It is found that the tensile shear strength of metals-plastics joint improved certainly because of the micropores existed on the surface of plastics. Roesner et al. [23, 24] conducted a laser welding test on a heterogeneous material of aluminum alloy and glass fiber reinforced nylon. With the surface of aluminum alloy pretreated by laser, the shear strength of the joint was improved effectively. To explore the function of the surface pretreated on the joint tensile shear strength, Rodríguez-Vidal et al. [25] processed microscopic patterns on HC420LA (a low alloy steel) surface by pulsed laser radiation. Then they used continuous wave (CW) fiber laser to achieve the connection between the HC420LA and PA6-GF30 (a glass fiber reinforced polyamide). They studied the influence of groove angle and groove spacing of linear microstructure on joint strength, and reported that groove spacing is the main factor affecting joint strength. The maximum shear strength of the joint is $12 \mathrm{MPa}$ when the groove spacing is $200 \mu \mathrm{m}$. Liu et al. [26] and Li [27] studied the effect of surface texture on the properties of 316L stainless steel and PET joints. By comparing textured 316L-PET joints and non-textured 316L-PET joints, they found that the tensile shear strength of different materials was improved through ablating the surface by laser irradiation.

The previous studies have reported that after laser beam irradiated on the metal surface, texture grooves are formed on the metal parts. During laser welding, the melting PET penetrated into the texture grooves at the metal surface to form the mechanical anchoring effect. Although surface texture can improve joint strength effectively, there has been no comprehensive understanding the effect of surface texture morphology on dissimilar welding between metal and plastic.

In this paper, surface texture and laser irradiation welding are applicated to aluminum alloy (1060Al)PET welding to obtain 1060Al-PET welding joints with high quality. The surface texture was produced using a galvanometer scanning fiber laser at different condition of marking defocusing and marking times. This paper focuses on the effect of different morphology parameters on the tensile shear strength of 1060Al-PET welding joints.

\section{Materials and Methods}

\subsection{Materials}

In the experiment, the metal material used was $1060 \mathrm{Al}$ with the dimension of $120 \mathrm{~mm} \times 25 \mathrm{~mm} \times 1.5 \mathrm{~mm}$. Compared to other metals, aluminum alloy has many advantages such as low density and high specific strength [28-30]. Chemical composition and physical properties of 1060Al are shown in Tables 1 and 2, respectively.

Table 1 The chemical composition of 1060Al (mass ratio, \%)

\begin{tabular}{llllllll}
\hline Al & Si & Mn & Cu & Mg & Zn & Mn & Ti \\
\hline 99.60 & $\leq 0.25$ & $\leq 0.05$ & $\leq 0.05$ & $\leq 0.05$ & $\leq 0.05$ & $\leq 0.05$ & $\leq 0.03$ \\
\hline
\end{tabular}


Table 2 Main physical properties of 1060Al

\begin{tabular}{lllll}
\hline $\begin{array}{l}\text { Density } \\
\left(\mathbf{g} / \mathbf{c m}^{3}\right)\end{array}$ & $\begin{array}{l}\text { Yield } \\
\text { strength } \\
(\mathbf{M P a})\end{array}$ & $\begin{array}{l}\text { Tensile } \\
\text { strength } \\
(\mathbf{M P a})\end{array}$ & $\begin{array}{l}\text { Elongation } \\
\mathbf{( \% )}\end{array}$ & $\begin{array}{l}\text { Thermal } \\
\text { conductivity } \\
\left(\mathbf{W} /\left(\mathbf{m} \cdot{ }^{\circ} \mathrm{C}\right)\right)\end{array}$ \\
\hline 2.7 & $\geq 75$ & $\geq 105$ & 3 & 234 \\
\hline
\end{tabular}

PET plates with dimension of $120 \mathrm{~mm} \times 25 \mathrm{~mm} \times 2 \mathrm{~mm}$ were used as the polymer during laser welding process. Physical properties and chemical formula of PET are exhibited in Table 3. The chemical formula of PET is $\left(\mathrm{C}_{10} \mathrm{H}_{8} \mathrm{O}_{4}\right)$ n, of which chemical structure contained the group ester carbonyl. In fact, because of active $\mathrm{C}$ atoms, ester carbonyl can easily react with metallic element during welding [26]. The component consists of $\mathrm{Al}$ and PET can not only ensure high connection strength but also meet the requirements of lightweight [31].

\subsection{Experimental Methods}

The experimental set-up for laser welding process of 1060Al-PET is shown in Figure 1. Two plates of different materials were lapped and fixed by two pressing plates by two bolts, each of which was equally submitted to a $35 \mathrm{~N} \cdot \mathrm{m}$ torque. The lap length was $50 \mathrm{~mm}$. A TruDisk 8002 (FD25) laser with maximum power of $8 \mathrm{~kW}$ and wavelength of $1060 \mathrm{~nm}$. And the spot size of laser beam was $0.2 \mathrm{~mm}$ at focal point. The conditions of $1060 \mathrm{Al}-$ PET laser welding were defocused distance of $60 \mathrm{~mm}$ and traveling speed of $v=0.9 \mathrm{~m} / \mathrm{min}$. As illustrated in Figure 1, laser welding was conducted in the direction perpendicular to the width dimension.

Before 1060Al-PET laser welding, lap surface of $1060 \mathrm{Al}$ was textured using a YLPM-1-4×200-20-20 galvanometer scanning fiber laser apparatus (IPG Inc.). Laser beam of high energy density was used by the laser apparatus to ablated the 1060Al surface exposed the focused laser beam. In this experiment, with the conditions of $20 \mathrm{~W}$ laser power and $500 \mathrm{~mm} / \mathrm{min}$ ablation speed, the texture morphology was changed by adjusting the defocus amount and marking times. Then laser welding was carried out on $1060 \mathrm{Al}$ and PET. At first, with the conditions of pulse frequency of $25 \mathrm{~Hz}$, pulse width of $20 \mathrm{~ms}$, pulse laser power (laser power) was optimized to obtain the lap joints with good performance. The range of laser power was from 1400 to $1800 \mathrm{~W}$. Then, the effects of surface texture morphology and the texture distance on the properties of 1060Al-PET joints were explored by orthogonal and single-factor optimization test, respectively.

After the experiment, Leica DM2700M optical microscope was used to observe the morphology of the joints weld. Then tensile tests were further carried out on the accepted joints to evaluate joint tensile shear strength (MPa) by TWC-2020 electronic universal testing machine (Sinotest Equipment Co., Ltd.). In addition, the plates of $1.5 \mathrm{~mm}$ and $2 \mathrm{~mm}$ should be fixed at both

Table 3 Main physical properties and chemical formulas of PET

\begin{tabular}{cccc}
$\begin{array}{c}\text { Density } \\
\left(\mathrm{g} / \mathrm{cm}^{3}\right)\end{array}$ & $\begin{array}{c}\text { Melting point } \\
\left({ }^{\circ} \mathrm{C}\right)\end{array}$ & $\begin{array}{c}\text { Decomposition } \\
\text { temperature } \\
\left({ }^{\circ} \mathrm{C}\right)\end{array}$ & $\begin{array}{c}\text { Transmittance } \\
(\%)\end{array}$ \\
\hline $\begin{array}{c}\text { Chemical } \\
\text { formula }\end{array}$ & 250 & 350 & $\begin{array}{c}\text { Bending strength } \\
(\mathrm{MPa})\end{array}$
\end{tabular}

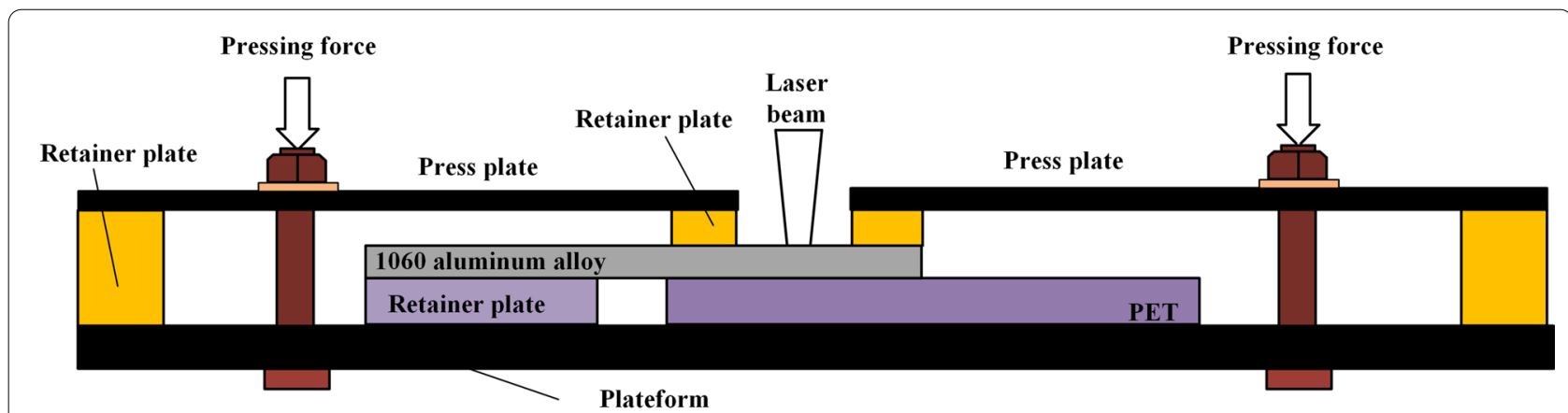

Figure 1 Schematic representation of the experimental set-up for laser irradiation welding 


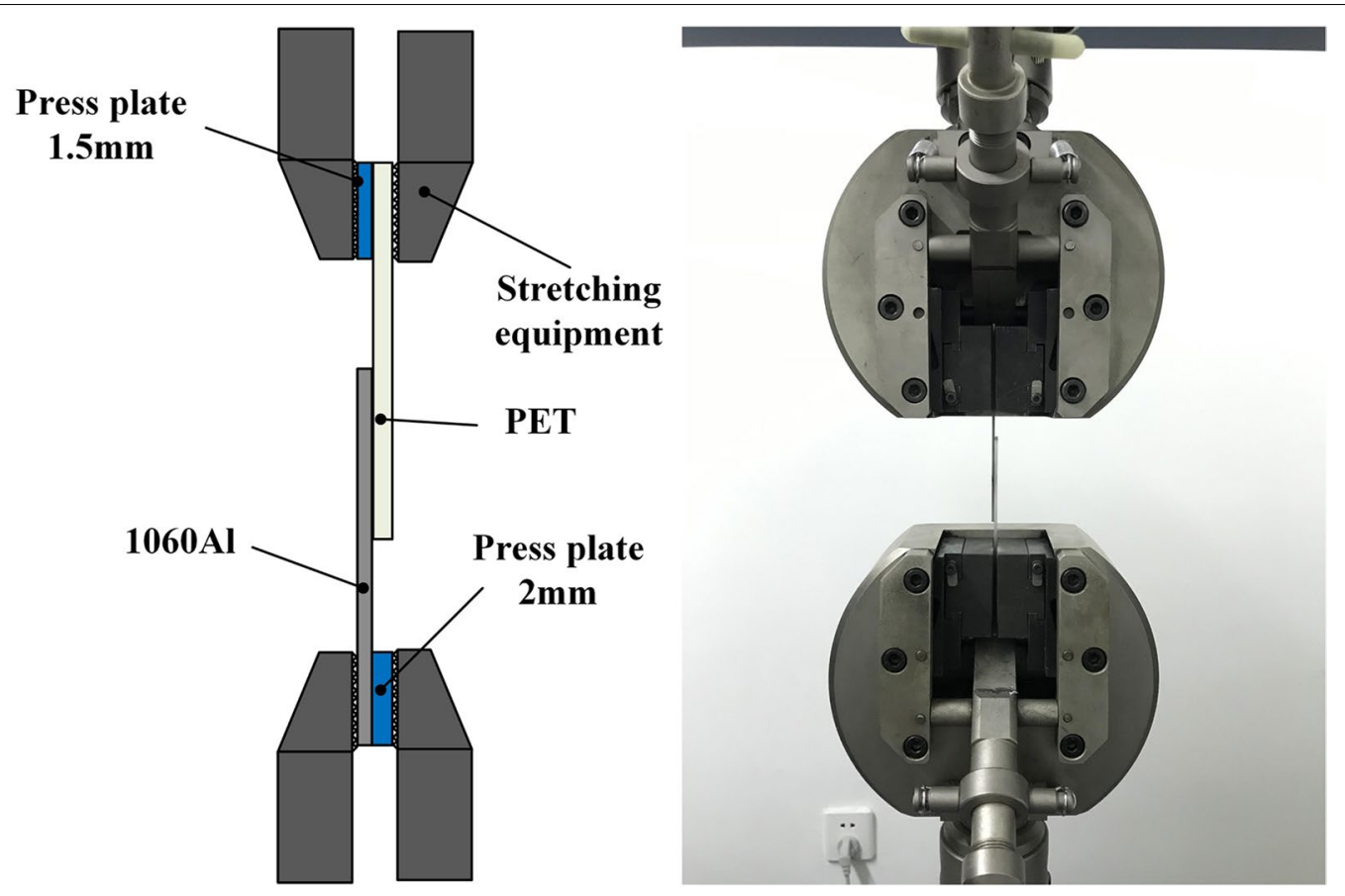

Figure 2 Schematic representation of the tensile shear experimental setup

ends of the tension specimens to keep the thickness of the clamping consistent (shown in Figure 2). Due to the received samples in this paper were non-standard tensile samples, so the equivalent tensile strength $(P)$ was used as the evaluation standard of joint strength. The equivalent tensile strength is expressed as follows: $P=$ $F / S$, in which $F$ is tensile force $(\mathrm{N})$ and the $S$ is crosssectional area of PET sheet $\left(\mathrm{mm}^{2}\right)$. In order to determine the effect of surface texture on the 1060Al-PET joint strength, the temperature field of welding process was stimulated. SEM-EDS was carried out on the joint samples to explore the content and distribution of the weld elements by a JSM-6510F scanning electron microscope. After the tensile tests, representative fracture samples were selected with residual PET on the surface of 1060Al removing to study on connection mechanism of the joints. Then Frontier FT-IR infrared spectrometer was carried out on the connection area without residual PET to detect the characteristic functional groups.

\section{Results and Discussion}

\subsection{Laser Welding Test of 1060Al-PET Joints with Surface Texture}

Before the experiments to optimize the laser power, the surface of $1060 \mathrm{Al}$ was textured by laser apparatus with the texture distance of $0.5 \mathrm{~mm}$. The marking and morphology parameters of surface texture are shown in Figure 3.
Typical bubble morphology of 1060Al-PET joints under different laser power are shown in Table 4. The bonding area was filled with bubbles. As the laser power increased, the bonding area and the number of bubbles increased obviously. The increase of laser power was always accompanied with the increase of accumulating heat. During the laser welding, PET started to decompose into bubbles because the temperature of the weld increased to a high level.

In order to evaluate the strength of the 1060Al-PET joints, the tensile shear test was performed. Figure 4 shows the joint strength as the function of laser power. The tensile strength had a trend to reach the maximum at laser power of $1600 \mathrm{~W}$, which was over $44 \mathrm{MPa}$. It can be viewed as the effect of energy input. At the given welding speed and defocusing amount, the laser power had direct bearing on the energy density received by $1060 \mathrm{Al}$ surface. The morphology of 1060Al-PET interface shows that at laser power of $1600 \mathrm{~W}$, the bubbles' volume and number are moderate and the tensile shear strength of joint reached the maximum. During the bubble expanding, the surface texture had a certain splitting effect on the bubble. However, as laser power increased (just like $1700 \mathrm{~W}$ and $1800 \mathrm{~W}$ ), the bubble volume was too large to reduce the splitting effect of surface texture. Consequently, the joint strength decreased instead. 


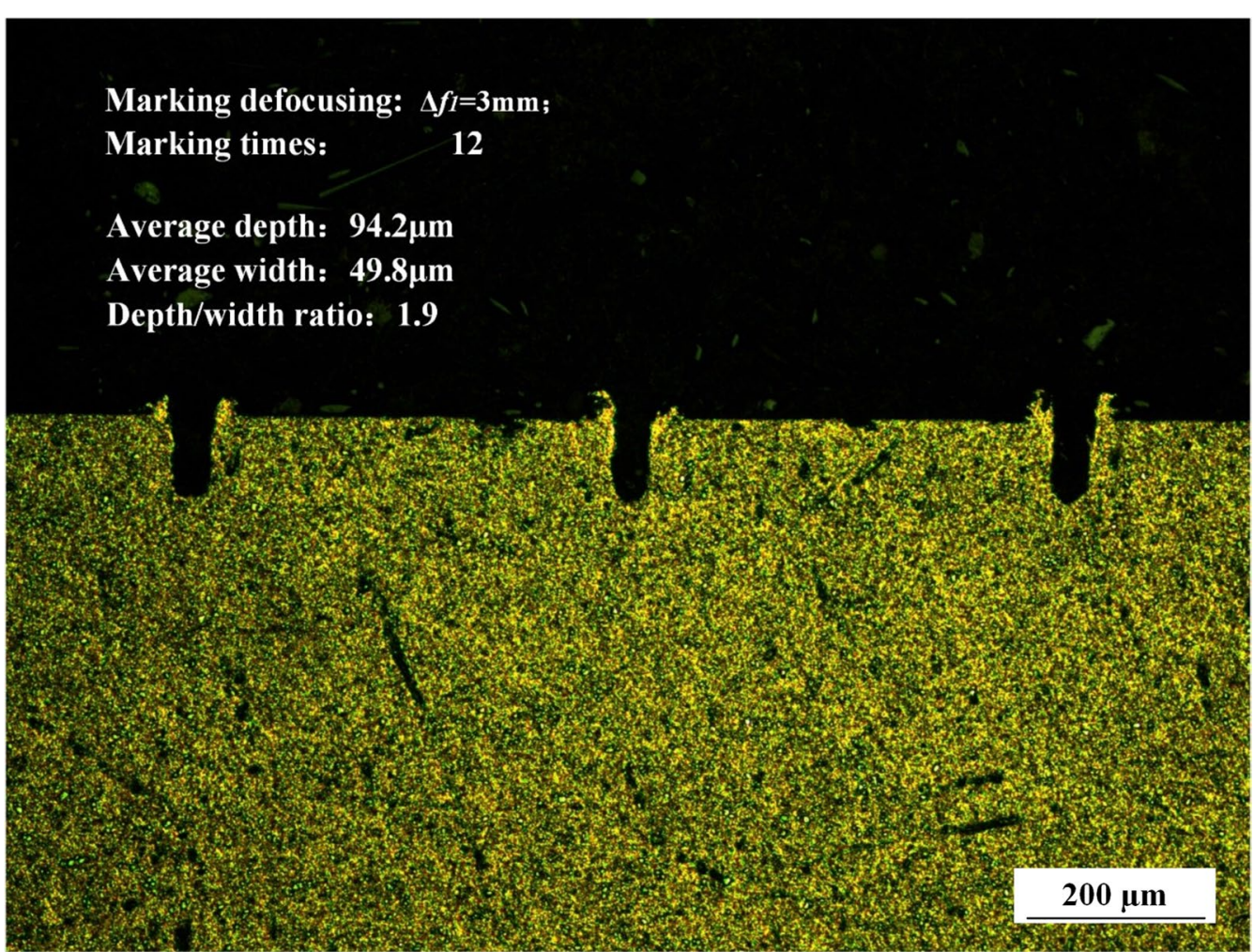

Figure 3 Marking and morphology parameters of surface texture

Table 4 Joint morphology characteristics under different laser power

\begin{tabular}{|c|c|c|c|c|c|}
\hline Laser power (W) & 1400 & 1500 & 1600 & 1700 & 1800 \\
\hline $\begin{array}{l}\text { Macroscopic } \\
\text { morphology }\end{array}$ & & & & & \\
\hline $\begin{array}{l}\text { Microscopic } \\
\text { morphology }\end{array}$ & & & & & \\
\hline Tensile strength $(\mathrm{MPa})$ & 38.75 & 42.45 & 44.09 & 38.66 & 38.0 \\
\hline
\end{tabular}

The fracture morphologies of 1060Al-PET joints under different laser power are shown in Figure 5 . With the increase of laser power, the fracture mode of the material changed from mixed fracture to base plastic fracture. Fixed fracture took place at the laser power of $1400 \mathrm{~W}$. At condition of low energy input, a little PET decomposed with some bubbles generated, which cannot form a high connection strength. In the tensile test, instant impact resulted in mixed fracture while fracture occurred. With the increase of laser power, necking fracture occurred at the weld edge. Base plastic fracture took place at the weld edge 


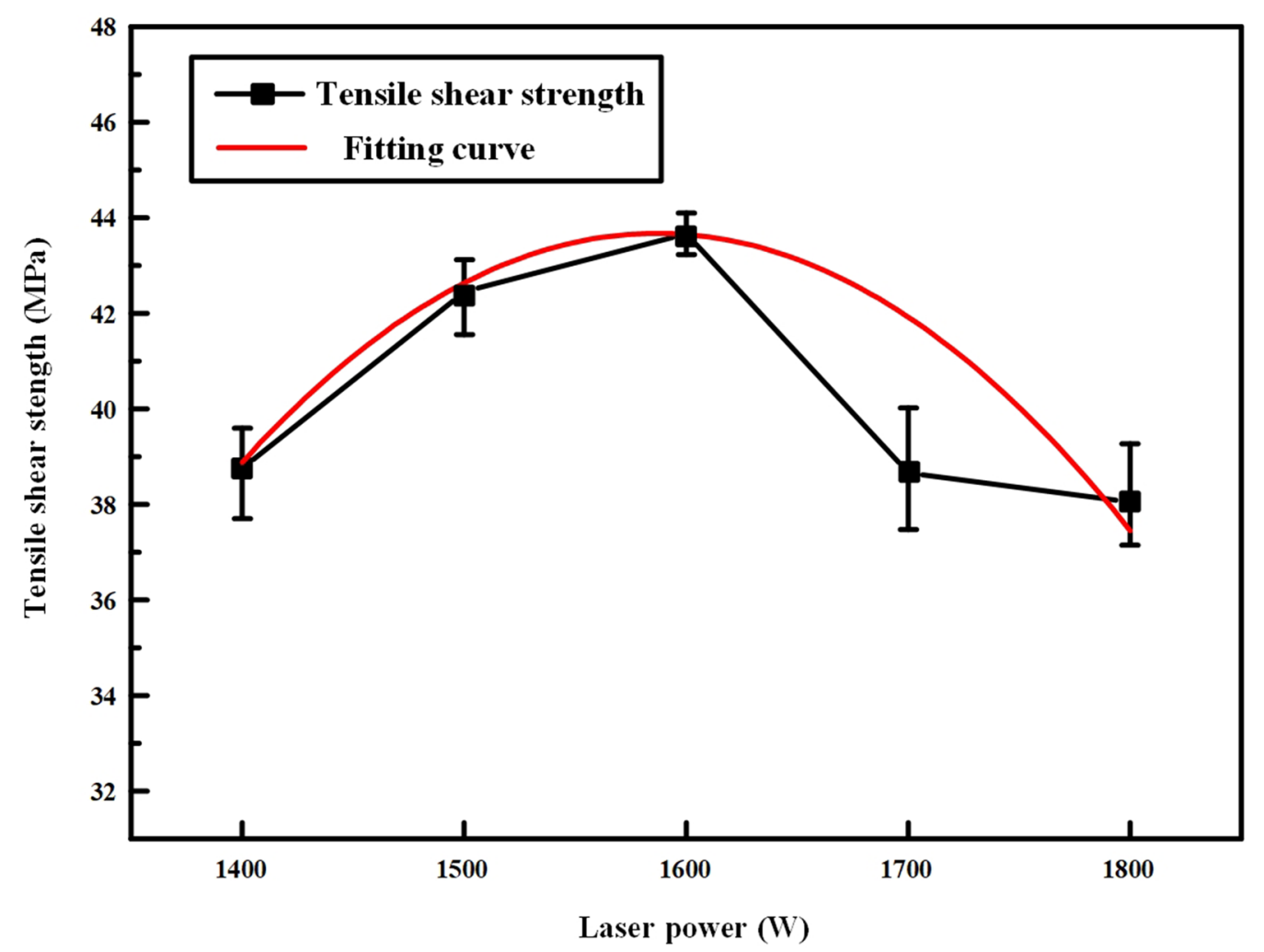

Figure 4 Tensile shear strength as a function of laser power

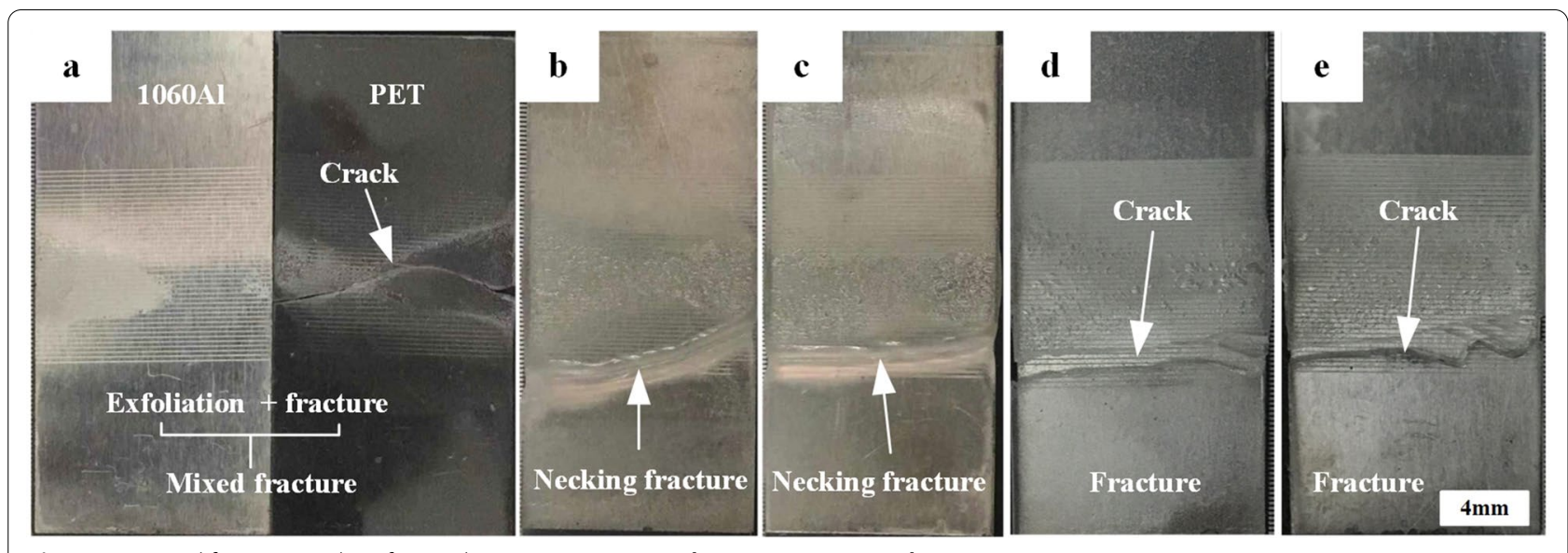

Figure 5 Typical fracture modes of 1060Al-PET joints: a 1400 W, b 1500 W, c 1600 W, d 1700 W, e 1800 W

at laser power of $1700 \mathrm{~W}$ and $1800 \mathrm{~W}$. And with the increase of power, there was a series of cracks appeared at the fracture.

\subsection{Effect of Texture Morphology and Marking Distance on 1060Al-PET Joints}

The effect of surface texture morphology on the properties of the 1060Al-PET joints was explored by orthogonal
Table 5 Parameters of the orthogonal optimization test

\begin{tabular}{ll} 
Marking defocusing $(\mathbf{m m})$ & Marking times \\
\hline 0 & 2 \\
1 & 5 \\
3 & 8 \\
5 & 12 \\
- & 15 \\
\hline
\end{tabular}


Table 6 The orthogonal optimization test results of texture marking defocusing and marking times

\begin{tabular}{|c|c|c|c|}
\hline Factor & $\begin{array}{l}\text { Marking } \\
\text { defocusing A } \\
(\mathrm{mm})\end{array}$ & $\begin{array}{l}\text { Marking } \\
\text { times B }\end{array}$ & Results (MPa) \\
\hline Test 1 & 0 & 2 & 35.79 \\
\hline Test 2 & 0 & 5 & 39.44 \\
\hline Test 3 & 0 & 8 & 41.69 \\
\hline Test 4 & 0 & 12 & 47.08 \\
\hline Test 5 & 0 & 15 & 46.98 \\
\hline Test 6 & 1 & 2 & 37.70 \\
\hline Test 7 & 1 & 5 & 34.58 \\
\hline Test 8 & 1 & 8 & 42.98 \\
\hline Test 9 & 1 & 12 & 46.36 \\
\hline Test 10 & 1 & 15 & 41.10 \\
\hline Test 11 & 3 & 2 & 39.18 \\
\hline Test 12 & 3 & 5 & 41.66 \\
\hline Test 13 & 3 & 8 & 46.90 \\
\hline Test 14 & 3 & 12 & 44.09 \\
\hline Test 15 & 3 & 15 & 43.11 \\
\hline Test 16 & 5 & 2 & 38.01 \\
\hline Test 17 & 5 & 5 & 39.73 \\
\hline Test 18 & 5 & 8 & 44.02 \\
\hline Test 19 & 5 & 12 & 43.33 \\
\hline Test 20 & 5 & 15 & 40.26 \\
\hline Average value 1 & 42.1 & 38.1 & \\
\hline Average value 2 & 40.8 & 38.2 & \\
\hline Average value 3 & 41.8 & 42.9 & \\
\hline Average value 4 & 41.1 & 43.3 & \\
\hline Average value 5 & & 41.6 & \\
\hline Range & 1.3 & 5.2 & \\
\hline Optimal combination & A1B4 & & \\
\hline
\end{tabular}

optimization test at laser power of $1600 \mathrm{~W}$. The texture morphology was featured by marking parameters such as marking defocusing and marking times. The parameters determined in this process are shown in Table 5.

The orthogonal optimization test results of texture marking defocusing and marking times are shown in Table 6. It was concluded that the influence of marking times on the joint strength was greater than that of texture marking defocusing. The maximum of 1060Al-PET joint tensile shear strength occurred at marking defocusing of $0 \mathrm{~mm}$, marking times of 12 . In this condition, the morphology parameters of surface texture are shown in Figure 6(a), which were $103.7 \mu \mathrm{m}$ in depth, $43.9 \mu \mathrm{m}$ in width, and the depth/width ratio was 2.3 . The best 1060Al-PET weld morphology is shown in Figure 6(b). It can be seen that the texture was good in shape and the internal wall was relatively smooth, which was conducive to PET melt filling. Moreover, there was flash phenomenon near the grooves edge during the laser marking, which can embed into PET matrix to enhance the anchoring effect during laser welding. In this condition, the number and shape of bubbles were moderate and the joint formed with well morphology. The maximum tensile strength of the joint was $47.08 \mathrm{MPa}$.

With the optimal parameters above, the effects of texture distance on the 1060Al-PET joint properties were explored. The joints morphologies at different texture distance are shown in Table 7 . The results show that the bonding area of joint increased in proportion to the increase in the texture distance from $0.3 \mathrm{~mm}$ to $0.7 \mathrm{~mm}$. The bubble volume increased distinctly as well. From the point of the microscopic morphologies, there was obvious influence of surface texture on the bubble morphology. When the texture distance was small, the process of

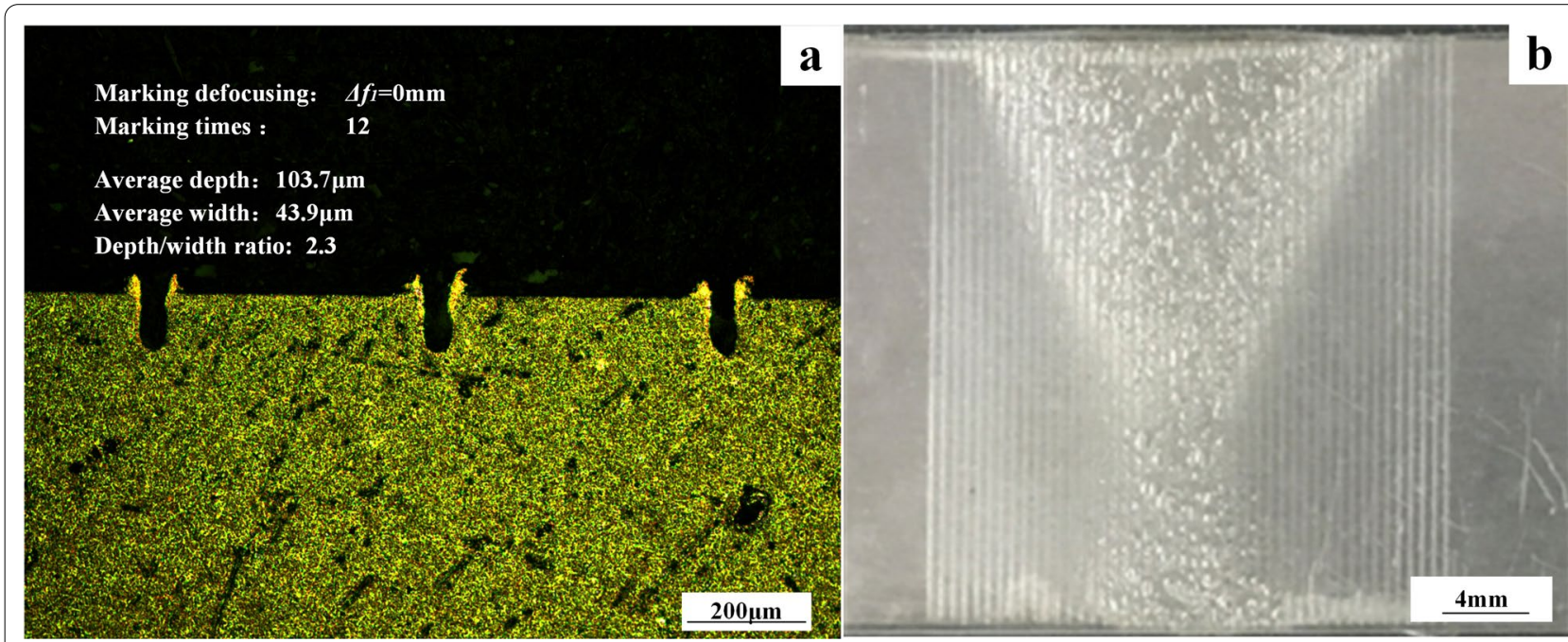

Figure 6 Morphology of the weld under the optimal parameters: a texture morphology, $\mathbf{b}$ weld morphology 
Table 7 Morphologies of 1060AI-PET joints at different texture distances

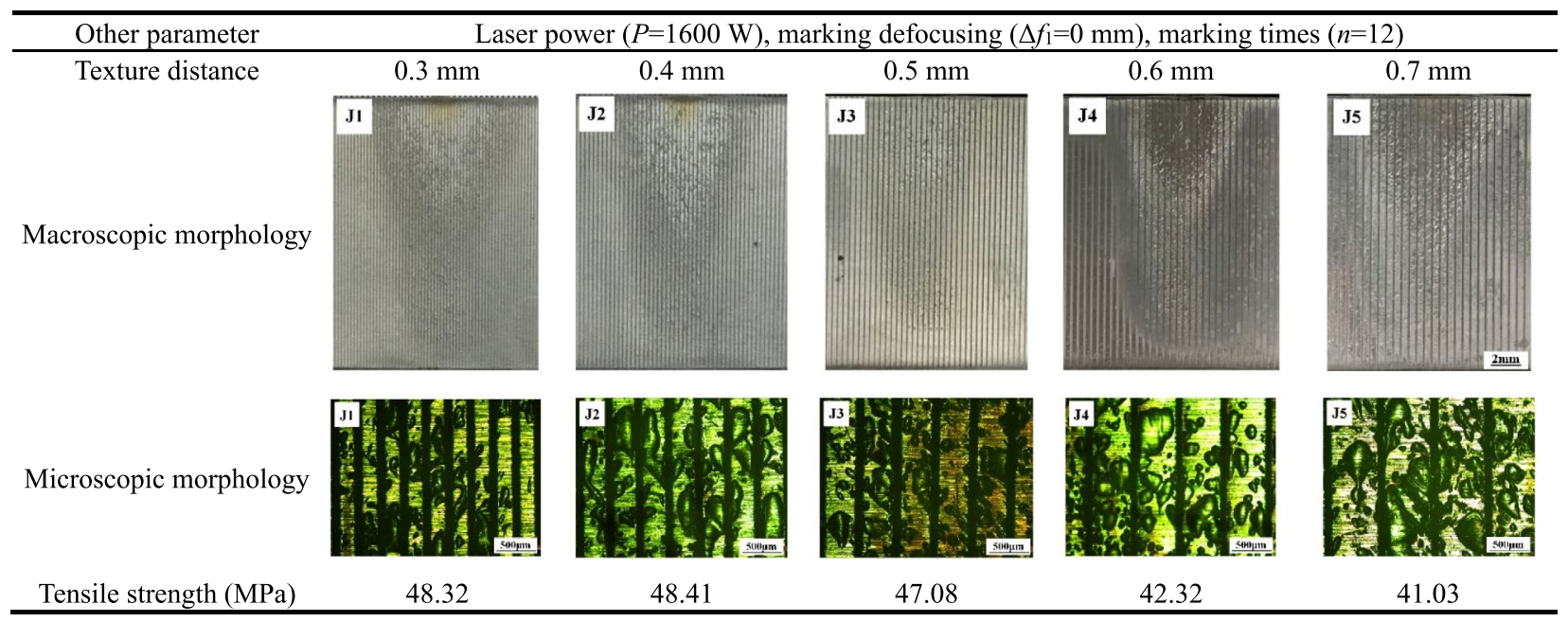

bubble growth was limited by the surface texture. With the increase of the texture distance, the limitation effect went down and bubbles volume increased.

Figure 7 shows the 1060Al-PET joint strength at different texture distances. The joint strength featured a tendency to increase with the decrease of texture distance. But when the texture distance decreased to $0.4 \mathrm{~mm}$, the joint tensile shear strength no longer improved and reached to $48.4 \mathrm{MPa}$, which was equal to $100 \%$ of the strength of PET matrix. Texture distance worked on 1060Al-PET joint properties in two aspects. For the first, bubbles in the weld beam were divided into smaller shapes by surface texture at lower distance during laser welding. For the other, with generated high pressure around the bubbles, the PET melt was pressed into the texture grooves, which can make the surface texture filled more tightly. Furthermore, the real connection area increased because of the texture grooves. With the decrease of texture distance, the density of texture grooves increased and the mechanical anchorage effect became more obvious. When the texture distance decreased to $0.4 \mathrm{~mm}$, the joint strength had reached $100 \%$ of that of the PET matrix strength. Therefore, the joint strength was no longer improved if the texture distance continued to decrease.

Fracture morphologies of 1060Al-PET joints at different texture distances are shown in Figure 8. During tensile shear tests, necking fracture took place at the edge of the weld beam at the texture distances of 0.3 $\mathrm{mm}, 0.4 \mathrm{~mm}$ and $0.5 \mathrm{~mm}$. With the increase of texture distance, the joint strength decreased and the fracture mode of joints turned to base plastic fracture.

\subsection{Function of the Texture Depth/Width Ratio on the Joint Properties}

The morphology parameters of surface texture had an important influence on 1060Al-PET joint properties. The relationship between strength of 1060Al-PET joint and depth/width ratio is shown in Figure 9. It can be seen from part I that the tensile shear strength of the 1060AlPET joints was relatively weak at the ratio of $0-1.5$. As for the other part, the tensile shear strength of the joints had a trend to first increase, to reach the maximum and then drop down with the depth/width ratio varied from 1.5 to 3.5. The received 1060Al-PET joints with high tensile shear strength were at the texture depth of 97-115 $\mu \mathrm{m}$ and depth/width ratio of $2-3$. The results above was illustrated next.

The schematic diagram of the tensile force of PET during tensile test at different depth/width ratios is shown in Figure 10. At the depth/width ratio of 1.1, the inner wall of the texture groove was inclined to the upper surface at an angle. This angle would cause an upward component of tensile force during the tensile shear test. Therefore, PET in the texture groove broke away from the texture easily, resulting in the failure of the joint. To make a comparison, the inner wall of the texture groove was nearly perpendicular to the upper surface at the depth/width ratio of 2.3. During tensile shear test, the force without upward component existed was perpendicular to the inner wall of the texture. Therefore, PET was not easy to escape from the texture groove and the anchoring effect of surface texture was reinforced a lot. 
The typical fracture modes comparation between different depth/width ratio is shown in Figure 11. The fracture of the joint was base material fracture of the weld edge as exhibited in Figure 11(a). According to the fracture location, the PET completely disintegrated from the texture groove on the surface of fracture location, and there was no PET residual in the texture grooves. The necking fracture at the depth/width ratio of 2.3 is shown in Figure 11(b). The necking fracture of PET matrix occurred at edge of the weld, and the texture

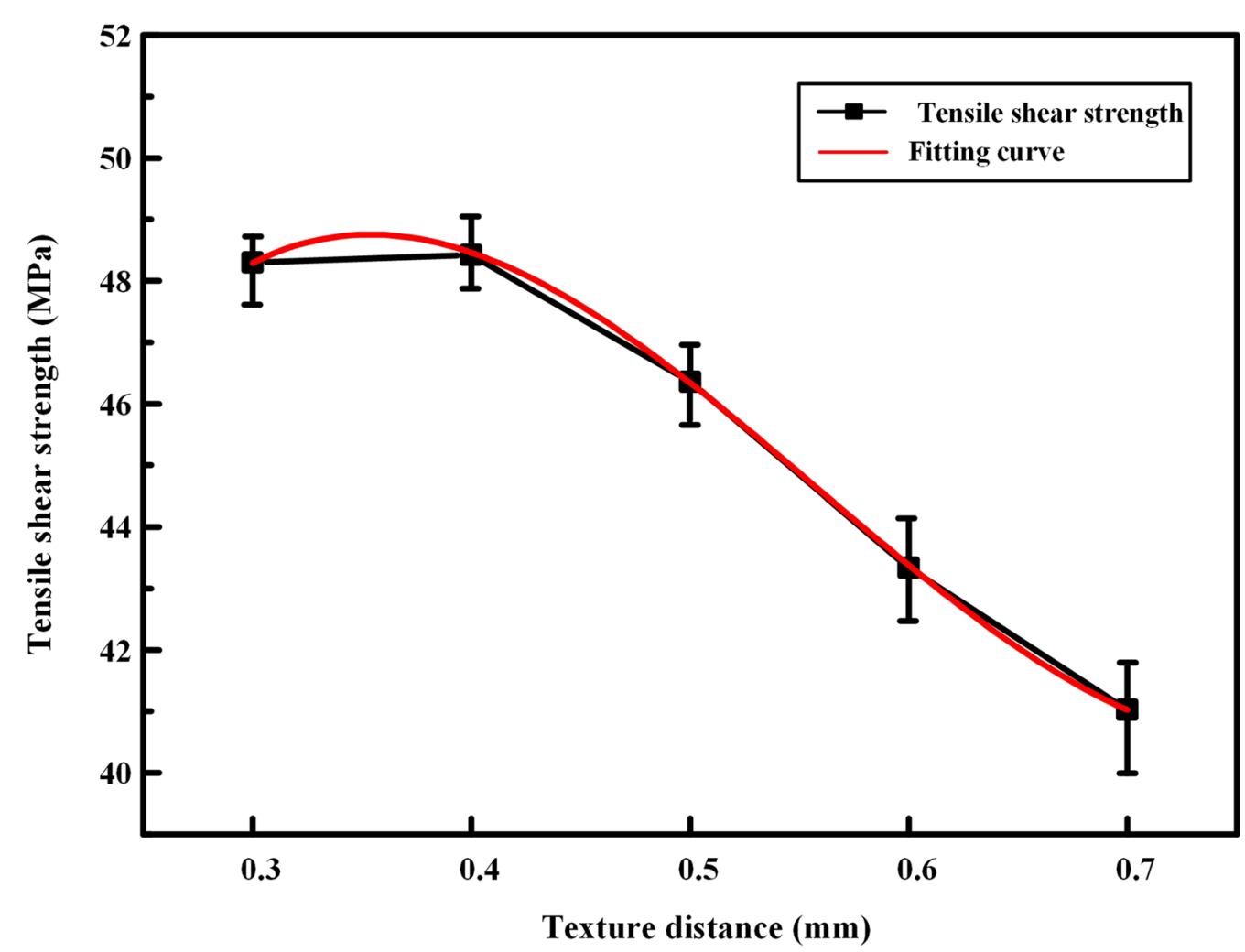

Figure 7 1060Al-PET joint strength at different texture distances

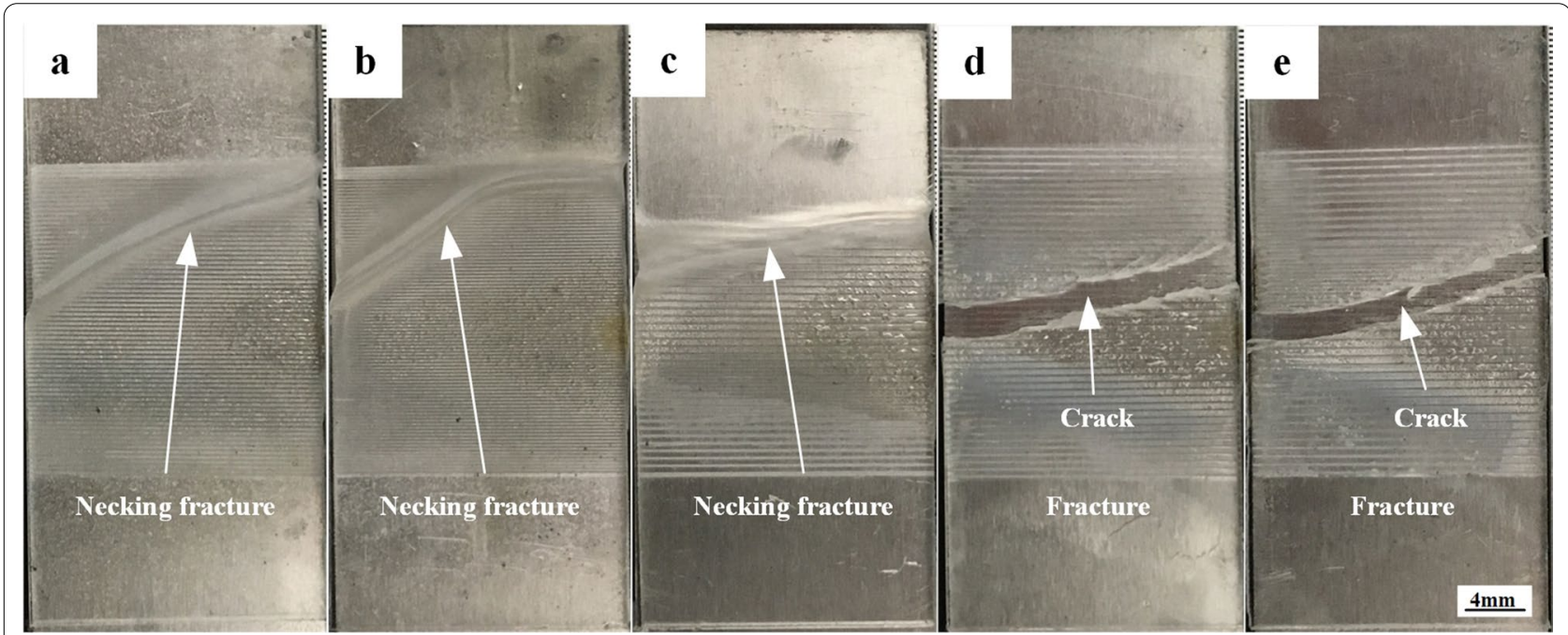

Figure 8 Fracture morphologies of 1060 Al-PET joints at different texture distances: a $0.3 \mathrm{~mm}, \mathbf{b} 0.4 \mathrm{~mm}, \mathbf{c} 0.5 \mathrm{~mm}$, d $0.6 \mathrm{~mm}, \mathbf{e} 0.7 \mathrm{~mm}$ 


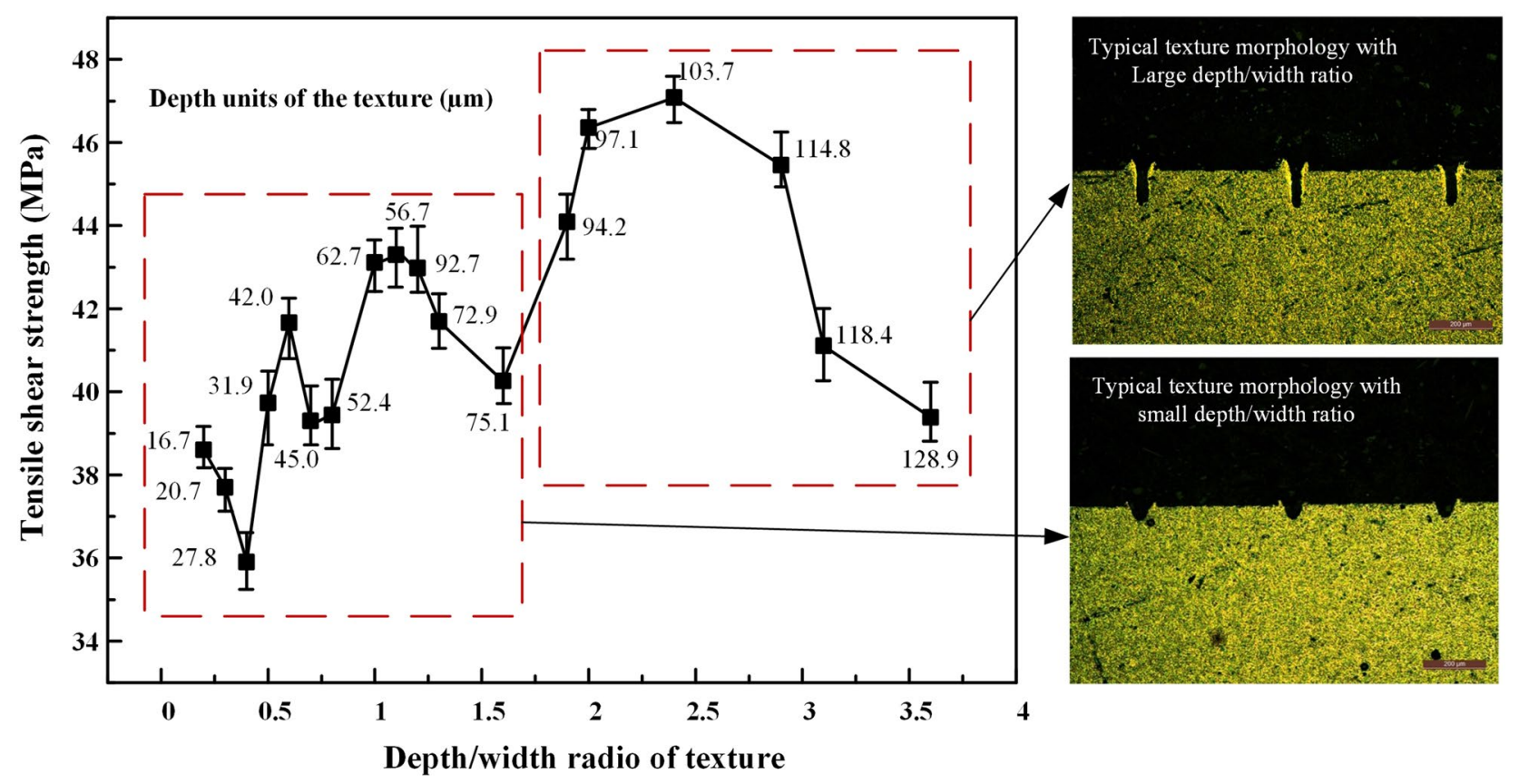

Figure 9 Relationship between strength of 1060AI-PET joint and depth/width ratio

grooves was well filled by PET without any separation or fracture. The results of tensile shear test were consistent with the analysis in Figure 10.

When the ratio reached more than 3 , the result of the tensile shear test was just the opposite. As is shown in Figure 12, because of the too large depth/width ratio, the groove was not fulfilled with PET and there was bubble in the bottom of the texture while the grooves of texture were fulfilled by PET melt at depth/width ratio of 2.3. Bubble in the groove went against tensile strength of the joint. Therefore, it was difficult to obtain the 1060AlPET joints with high strength at too large depth/width ratio.

\subsection{Temperature Simulation in 1060Al-PET Laser Welding Process}

As we all know, temperature is one of the most crucial factors to determine the joint properties. Thus, it is necessary to conduct the temperature simulation of the bonding area. Geometrical model was consist of the 1060Al plate of $20 \mathrm{~mm} \times 25 \mathrm{~mm} \times 1.5 \mathrm{~mm}$ and PET plate of $20 \mathrm{~mm} \times 25 \mathrm{~mm} \times 2 \mathrm{~mm}$. In order to simplify the simulation process, the texture morphology was scaled up by selecting the texture width of $0.2 \mathrm{~mm}$ and the depth-width ratio of 2 . Geometrical model is shown in Figure 13. The physical properties of 1060Al and PET are presented in Table 8. In the temperature simulation, the change of thermophysical properties with temperature is not considered. SYSWELD software was employed to conduct the numerical simulation of the developed model. Because the power density distribution of laser beam is close to the Gaussian distribution, Gauss heat source was used during the experiment [32].

Figure 14 presents the results of temperature simulation, as compared to the non-textured 1060Al-PET joint with the highest temperature of $509{ }^{\circ} \mathrm{C}$, the high temperature region in textured joint was more concentrated and the highest temperature reached to 526 ${ }^{\circ} \mathrm{C}$. Since the difference of the melting temperature between 1060Al and PET was very large, the generated heat causes PET zone at interface to be melted and fused, while the 1060Al was kept in solid state. The joint with high tensile shear strength was formed in this condition. When the laser worked on the metal surface, the heat was transferred to the lap surface mainly via the $1060 \mathrm{Al}$ matrix. On the one hand, the exist of texture grooves reduced the heat transfer efficiency, leading to temporary heat accumulation. On the other hand, the texture grooves were filled with the molten PET because of the high pressure. In consideration of the huge difference between 1060Al and PET matrix, the heat dissipation at interface was impeded in course of laser welding. Therefore, the high-temperature area was more concentrated in the welding process. 


\subsection{Bonding Mechanism of 1060Al-PET Welding Joints}

To have an understanding on bonding mechanism between metal and PET, mechanical anchoring effect was discussed in this section. It should be also pointed that the chemical bond between PET and metal played a significant role in the joint mechanical properties.

Figure 15 shows schematic diagram of the function of surface texture for mechanical anchoring effect. During laser welding, the temperature of weld reached to over $350{ }^{\circ} \mathrm{C}$ (degradation temperature of PET), there would be a lot of bubbles around the surface texture. For the first, the melt fluidity can be promoted as the bubbles to grow and connected with each other during interaction time. The high pressure caused by generation and rapid expansion of these bubbles made the molten PET pressed into the texture grooves, which can make the surface texture filled more tightly. For the other, surface texture not only formed a series of grooves on the metal surface, but also produced flash embedded into the PET. Therefore, mechanical anchoring effect achieved with the groove and flash on the interface of weld. Surface texture can give full play to the role of mechanical anchoring effect for its direction perpendicular to the tensile direction [34, 35], which significantly improved the tensile shear strength of the joint.

Microstructure at the interface of 1060Al-PET joint is illustrated in Figure 16. In order to further confirm about the characteristics during laser welding of 1060Al to PET, typical joint was selected to be examined by SEM-EDS. Figure 17 indicates SEM-EDS analytical results of the texture groove and interface in

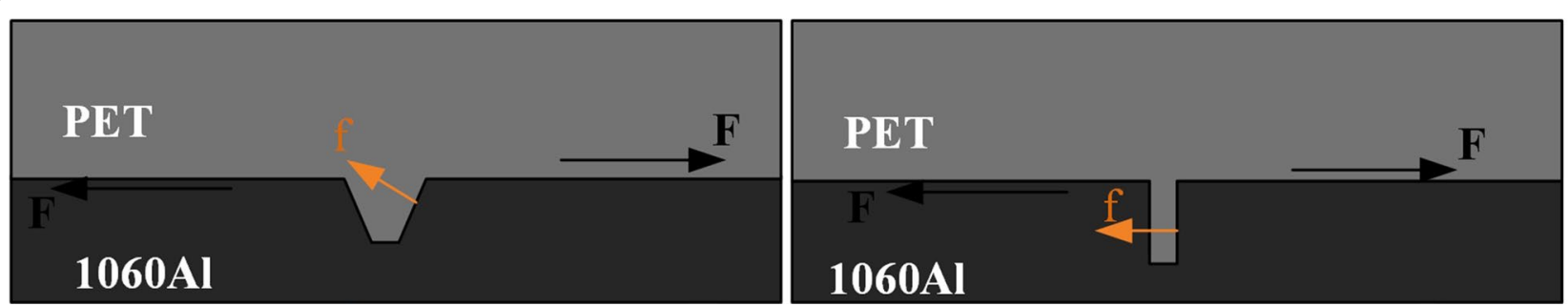

Figure $\mathbf{1 0}$ Schematic diagram of the tensile force of PET at different depth/width ratios: a depth/width ratio of 1.1, $\mathbf{b}$ depth/width ratio of 2.3
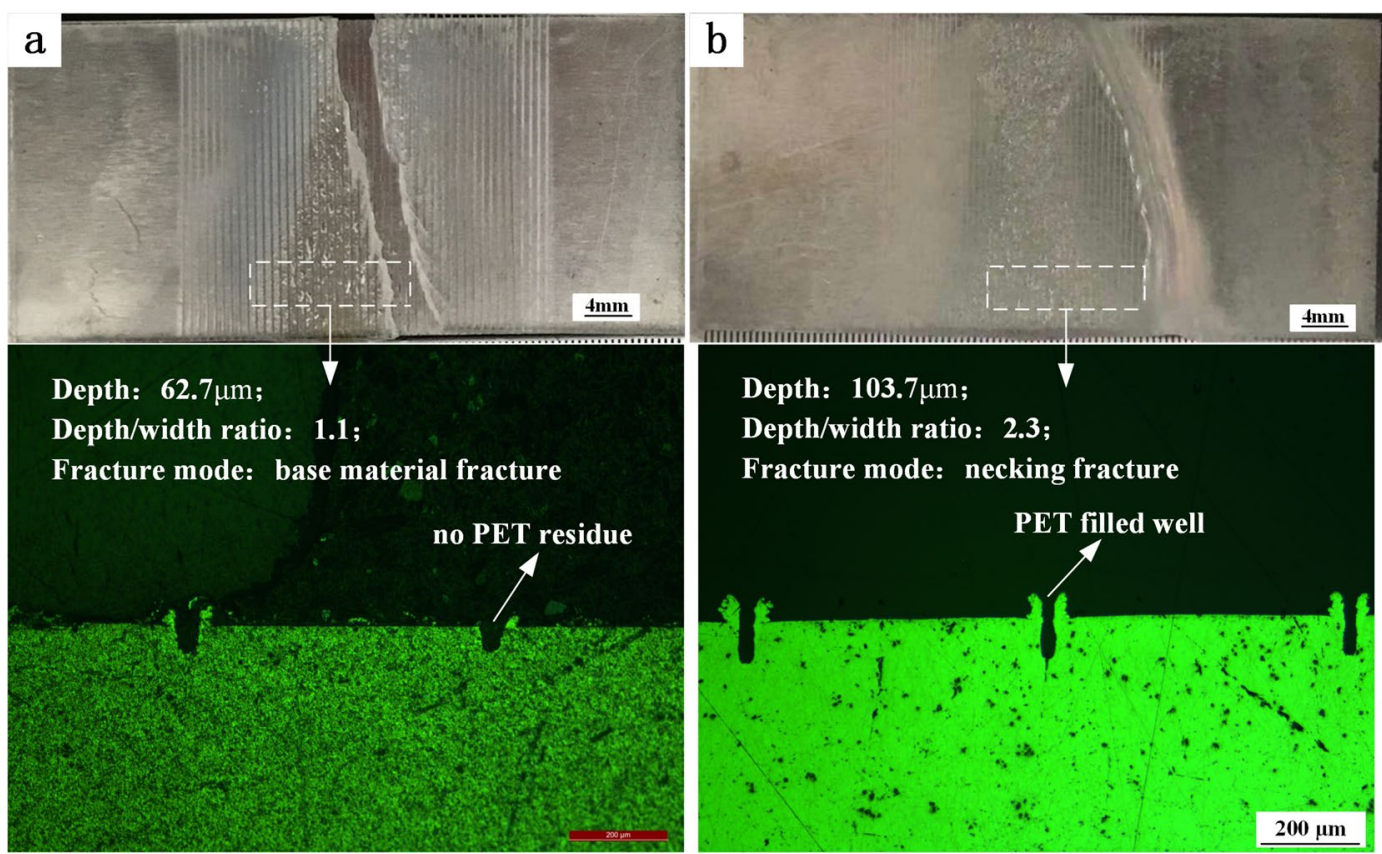

Figure 11 Typical fracture morphology comparation between different depth/width ratio: a depth/width ratio of 1.1, b depth/width ratio of 2.3 


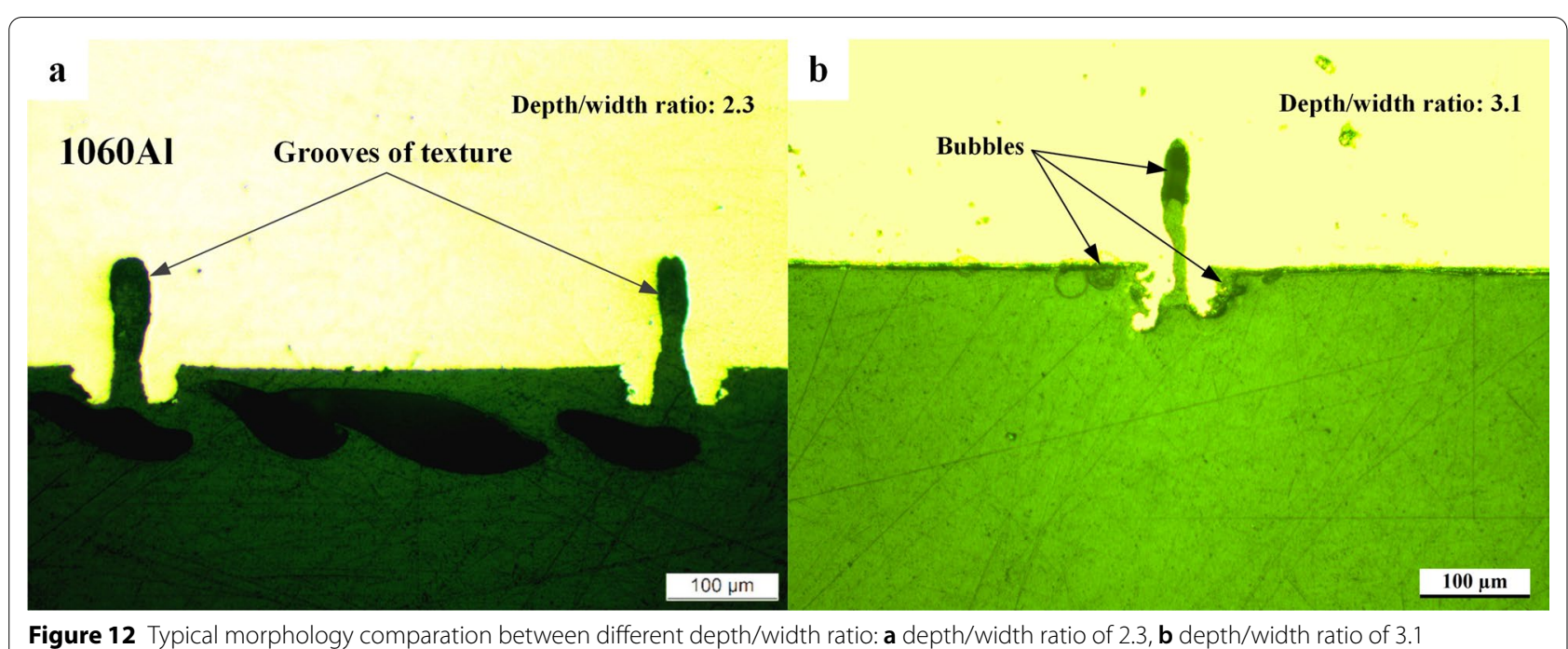

Figure 12 Typical morphology comparation between different depth/width ratio: a depth/width ratio of 2.3, b depth/width ratio of 3.1
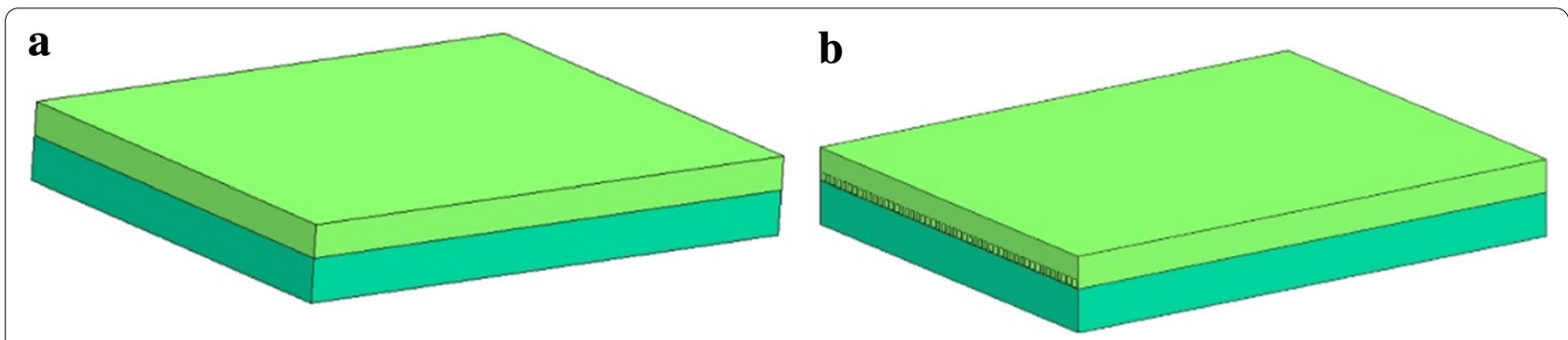

Figure 13 Geometrical model of temperature simulation: a joint without surface texture, $\mathbf{b}$ joint with surface texture

Figure 16. It can be seen that the texture groove was fulfilled with the molten PET at the joint interface, then the chemical compositions of the representative element of the point analyzed in point 1 of the molten PET were composed of $76.88 \mathrm{wt} \%$ carbon, $22.94 \mathrm{wt} \%$ oxygen. The joint interface was represented by point 2. Chemical compositions of the elements detected in point 2 contained 7.39 wt\% carbon, 3.58 wt\% oxygen. Because of the fact that there is no carbon existed in the $1060 \mathrm{Al}$, it was conformed that the carbon at the interface had complexed with the 1060Al. The results of linear scanning performed on the texture and interface is shown in Figure 17(b). The carbon element in the groove and at the interface was significantly increased, which was consist with the result with the point scanning. It was concluded that the surface texture not only significantly enhanced the joint strength by the mechanical anchoring effect, but also increased the actual bonding area of the weld. In addition, the increased bonding area was beneficial to the mechanical properties of the joint.
Table 8 Physical properties of 1060Al and PET [26, 33]

\begin{tabular}{lll}
\hline Property & 1060AI & PET \\
\hline Density $\left(\mathrm{g} / \mathrm{cm}^{3}\right)$ & 2.70 & 1.68 \\
Specific heat capacity $\left(\mathrm{J} /\left(\mathrm{kg} \cdot{ }^{\circ} \mathrm{C}\right)\right)$ & $0.88 \times 10^{3}$ & $2.50 \times 10^{3}$ \\
Thermal conductivity $\left(\mathrm{W} /\left(\mathrm{m} \cdot{ }^{\circ} \mathrm{C}\right)\right)$ & 234 & 0.08 \\
Elasticity modulus $(\mathrm{MPa})$ & 68 & 2 \\
Poisson's ration & 0.35 & 0 \\
Melting point $\left({ }^{\circ} \mathrm{C}\right)$ & 660 & 280 \\
\hline
\end{tabular}

Infrared spectrum analysis was carried out on specimens to explore the forms of combination between $1060 \mathrm{Al}$ and PET molecules. There were two characteristic absorption peaks at $1747 \mathrm{~cm}^{-1}$ and $1146 \mathrm{~cm}^{-1}$ in Figure 18. There is a truth that the range of carbonyl $(\mathrm{C}=\mathrm{O})$ vibration absorption peak is $1900-1680 \mathrm{~cm}^{-1}$, of which the ketone is $1720-1715 \mathrm{~cm}^{-1}$, the aldehyde is $1740-1720 \mathrm{~cm}^{-1}$, and the ester is $1750-1735 \mathrm{~cm}^{-1}$ [28]. 
Therefore, the $\mathrm{C}=\mathrm{O}$ group corresponding to the characteristic absorption peak at $1747 \mathrm{~cm}^{-1}$ was an ester carbonyl group. The characteristic absorption peak at 1146 $\mathrm{cm}^{-1}$ in Figure 18 was corresponded to the ether bond because the range of ether bond (C-O-C) was $1300-1050$ $\mathrm{cm}^{-1}$. On the one hand, the carbon atoms in the $\mathrm{C}=\mathrm{O}$ group were active carbon atoms, which were electronegative and easy to gain electrons. During laser welding, $\mathrm{Al}$ element bonded with carbon in carbonyl groups to form metal complexes. On the other hand, the oxygen on the ether bond was relatively stable, and it was not easy for metals to bond. To sum up the results of EDS and spectrum analysis, it was concluded that the $\mathrm{CO}$ group in PET had complexation reaction with $\mathrm{Al}$ elements in 1060Al to form high-strength chemical bond. High-strength chemical bond was an important factor for high joint strength. This conclusion is consistent with many related studies $[16,26,27]$.

\section{Conclusions}

Surface texture and laser irradiation welding are applicated to 1060Al-PET welding to obtain 1060Al-PET joints with high quality. Tensile shear test showed that the laser power and parameters of texture marking had great influences on the bond strength. The function of texture morphologies on joint strength and bonding mechanism were investigated. The results can be summarized as follows.

(1) $1060 \mathrm{Al}$ with surface texture was successfully joined to PET by laser irradiation welding from metal side over a wide range of welding parameters.

(2) Tensile shear tests demonstrated that at the conditions of texture depth of $97-115 \mu \mathrm{m}$, depth/width ratio of $2-3$, spacing of no more than $0.4 \mathrm{~mm}$, 1060Al-PET joint can be obtained with good performance. The maximum tensile shear strength

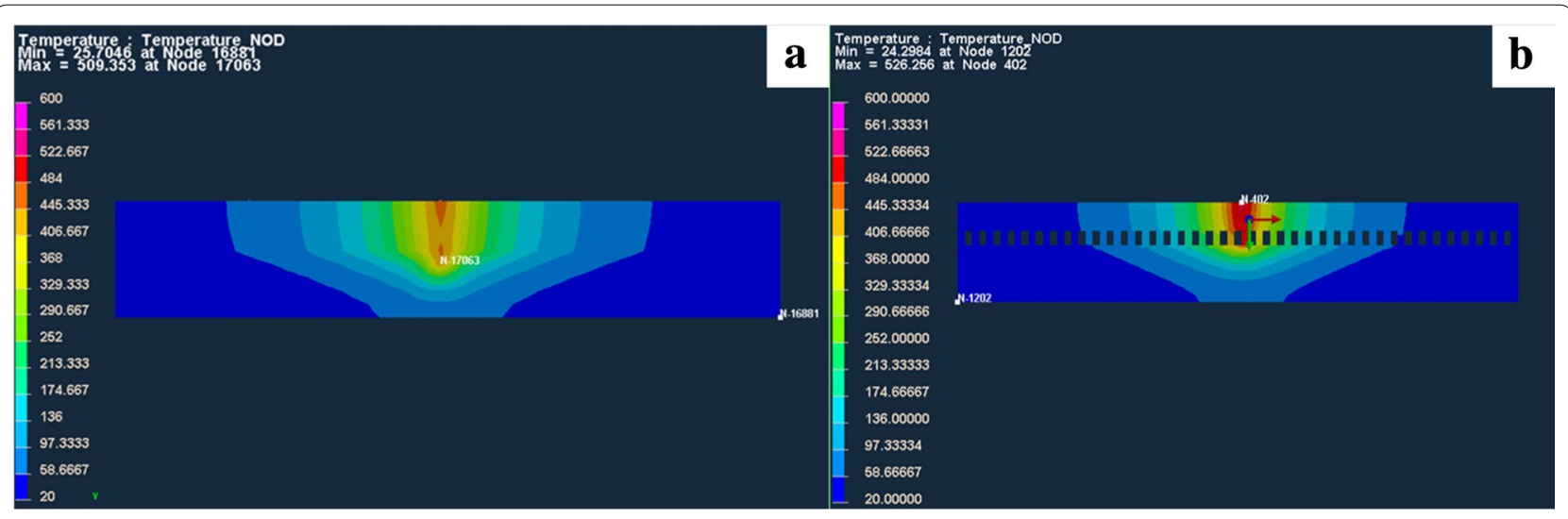

Figure 14 Temperature simulation results of 1060AI-PET welding process: a 1060Al-PET joint without texture, b 1060AI-PET joint with texture

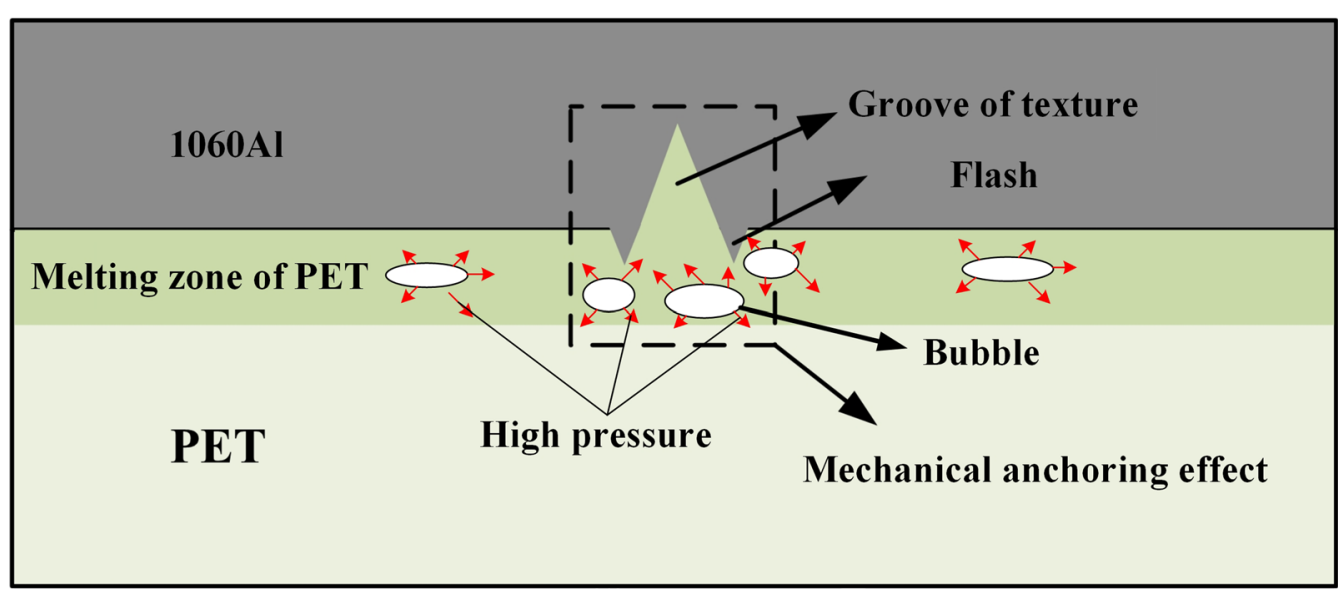

Figure 15 Schematic diagram of the function of surface texture for mechanical anchoring effect 
reached to $48.4 \mathrm{MPa}$, which was equal to $100 \%$ of the strength of PET matrix. With the same welding parameters, the maximum strength of 1060Al-PET joint without texture $33.75 \mathrm{MPa}$ [17]. It demonstrated the surface texture can enhance the connect strength of the 1060Al-PET.

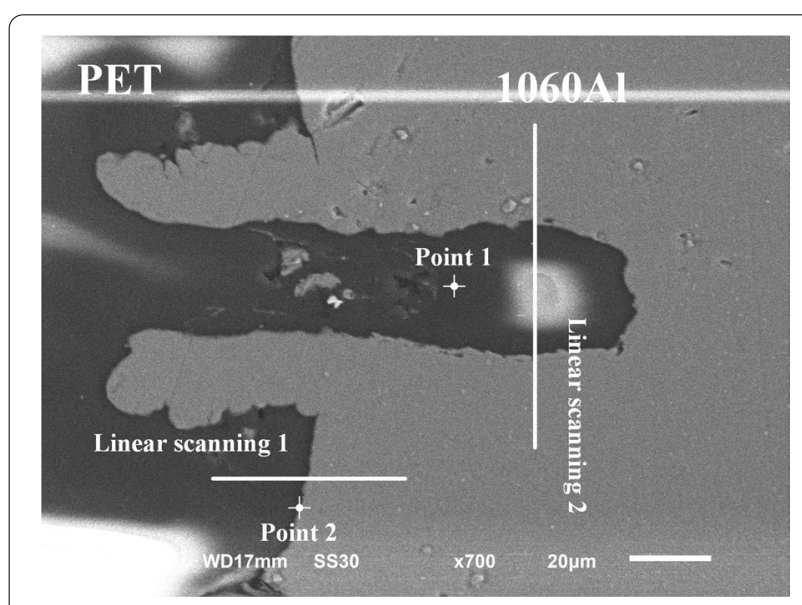

Figure 16 Microstructure of 1060Al-PET joint under observation of SEM
(3) The mechanical force of joint was strengthened contributed to mechanical anchorage formed by surface texture and PET. The depth-width ratio of the texture grooves affected the tensile shear process of the joint. PET in the texture groove broke away from the texture easily due to an upward component of tensile force at low depth-width ratio. When the ratio was too large, mechanical anchorage effect would be reduced because the groove was not fulfilled with PET and there was bubble in the bottom of the texture.

(4) Surface texture affected the heat transfer process of welding. On the one hand, the exist of texture grooves reduced the heat transfer efficiency, leading to temporary heat accumulation. On the other hand, in consideration of the huge difference between 1060Al and PET matrix, the heat dissipation at interface was impeded in course of laser welding.

(5) The bonding mechanism of the 1060Al-PET joints was composed of mechanical bonding and chemical bonding.

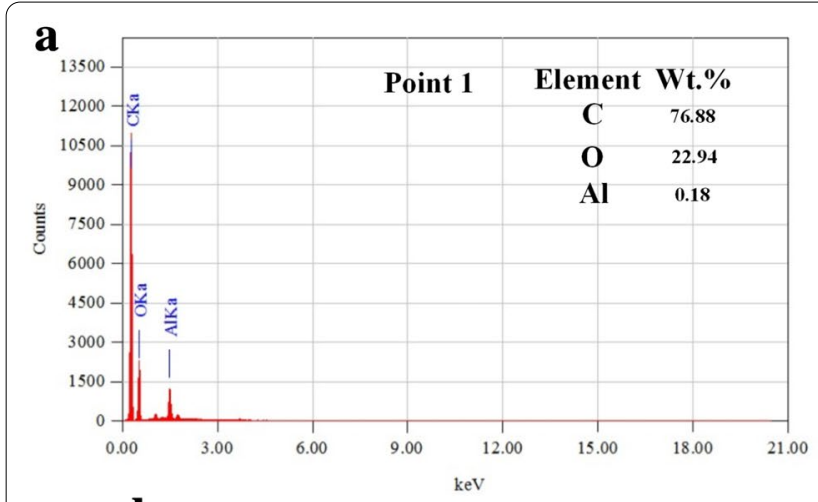

b

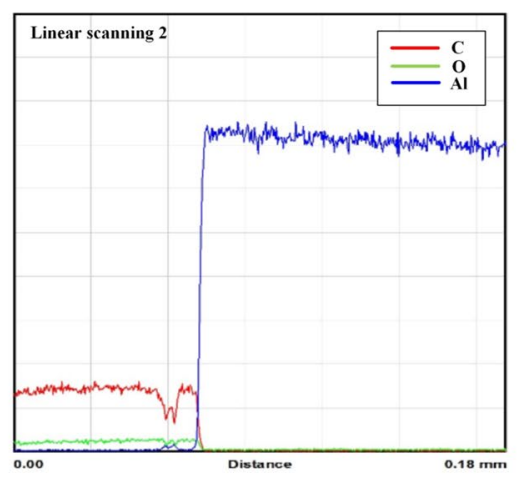

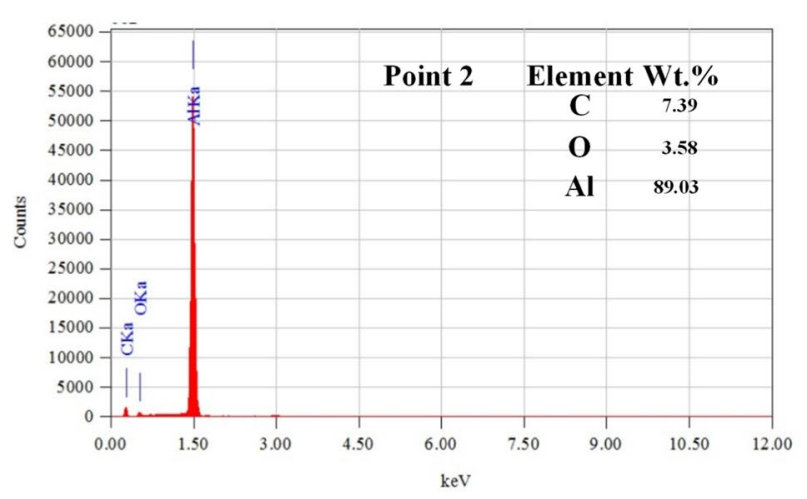

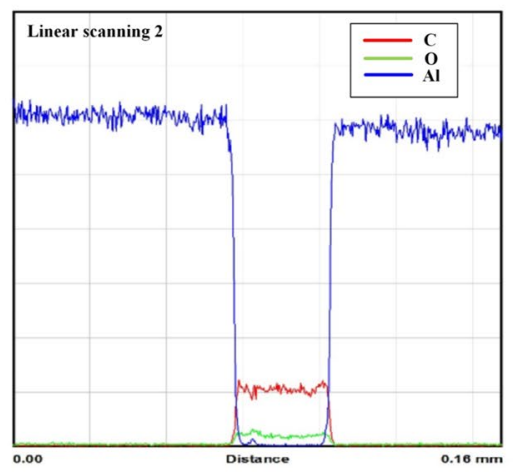

Figure 17 SEM-EDS results of the interface between metal and PET: a point scanning, $\mathbf{b}$ linear scanning 


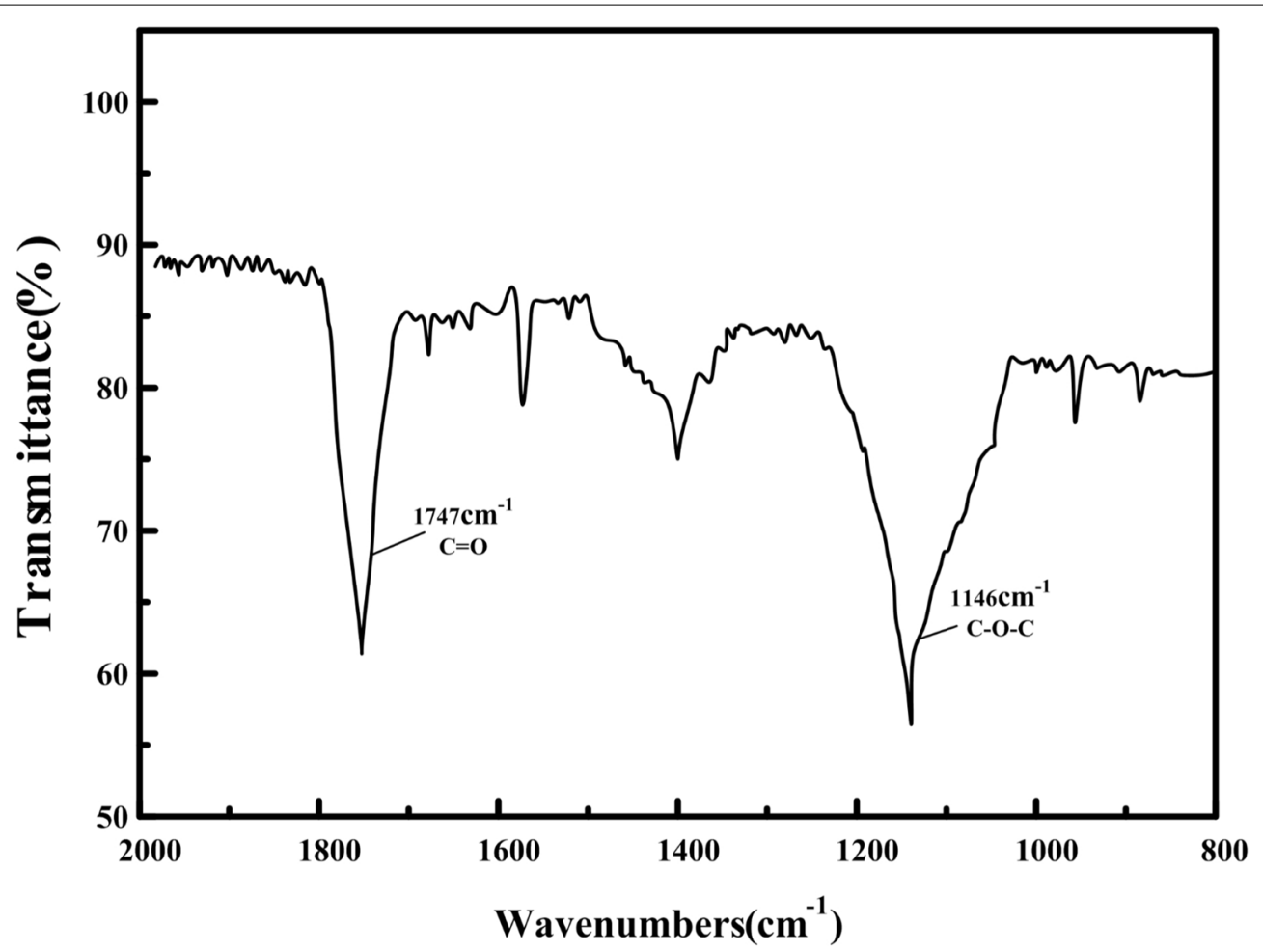

Figure 18 Infrared absorption spectra of 1060Al surface on welding zone without residual PET

\section{Acknowledgments}

Not applicable.

\section{Authors' Contributions}

$J L$ was in charge of the whole trial; YCD wrote the manuscript; WFC and TJ assisted with sampling and laboratory analyses. YS supervised the study. All authors read and approved the final manuscript.

\section{Authors' Information}

Jia Liu, born in 1983, is currently an associate professor at Changchun University of Science and Technology, China. He received his PhD degree from Changchun University of Science and Technology, China, in 2012. His research interests include laser welding, laser composite processing, and its finite element simulation technology. Tel: +86-431-85582207. E-mail: liujia@cust.edu.cn. Yuchi Dai, born in 1994, is currently a PhD candidate at Engineering Research Center of Laser Processing, Changchun University of Science and Technology, China. E-mail:1377416376@qq.com.

Yan Shi, born in 1972, is currently a professor at Changchun University of Science and Technology, China. He received his PhD degree from Changchun University of Science and Technology, China, in 2007. E-mail: shiyan@cust.edu.cn. Wenfu Cui, born in 1993, is currently a master candidate at Engineering Research Center of Laser Processing, Changchun University of Science and Technology, China. E-mail:17543067527@163.com.

Tao Jiang, born in 1992, is currently a master candidate at Engineering Research Center of Laser Processing, Changchun University of Science and Technology, China.E-mail:815793095@qq.com.

\section{Funding}

Supported by Natural Science Foundation of Jilin Province, China (20200201230JC).

\section{Competing Interests}

The authors declare no competing financial interests.

\begin{abstract}
Author Details
${ }^{1}$ School of Electromechanical Engineering, Changchun University of Science and Technology, Changchun 130022, China. ${ }^{2}$ Engineering Research Center of Laser Processing for Universities of Jilin Province, Changchun 130022, China. ${ }^{3}$ National Base of International Science and Technology Cooperation in Optics, Changchun 130022, China.
\end{abstract}

Received: 22 December 2020 Revised: 18 June 2021 Accepted: 9 November 2021

Published online: 11 December 2021

\section{References}

[1] M Liu, D Ouyang, J Zhao, et al. Clear plastic transmission laser welding using a metal absorber. Optics \& Laser Technology, 2018, 105: 242-248.

[2] YYWang, A H Wang, Z K Weng, et al. Laser transmission welding of Clearweld-coated polyethylene glycol terephthalate by incremental scanning technique. Optics \& Laser Technology, 2016, 80: 153-161.

[3] $\mathrm{HWu}, Y$ Xin. Molecular dynamics simulation of gas diffusion behavior in polyethylene terephthalate/aluminium/polyethylene interface. Composite Interfaces, 2017, 24(9): 915-926.

[4] H R Jiang. Laser transmission welding research and numerical simulation of grafted polyethylene and nylon 66. Zhenjiang: Jiangsu University, 2016. (in Chinese)

[5] B Latifa, F F Zohra, H Said. Study of raw and recycled polyethylene terephthalate by meaning of TGA and computer simulation. Advances in Polymer Technology, 2020: 1-7.

[6] J Frketic, T Dickens, S Ramakrishnan. Automated manufacturing and processing of fiber-reinforced polymer (FRP) composites: An additive review of contemporary and modern techniques for advanced materials manufacturing. Additive Manufacturing, 2017, 14:69-86. 
[7] D Huang, XZhao. Novel modified distribution functions of fiber length in fiber reinforced thermoplastics. Composites Science and Technology, 2019, 182: 107749.

[8] B Zhang, X Chen, K Pan, et al. J-integral based correlation evaluation between microstructure and mechanical strength for FSSW joints made of automotive aluminum alloys. Journal of Manufacturing Processes, 2019, 44: 62-71

[9] O A Ganilova, M P Cartmell, A Kiley. Experimental investigation of the thermoelastic performance of an aerospace aluminium honeycomb composite panel. Composite Structures, 2020, 257(3): 113-159.

[10] ZY Wan, X Zhou, Z Zhang. Calculations of microstructural changes and predictions of mechanical properties in friction stir welding of AA6005 T6. Journal of Mechanical Engineering, 2018, 54(8): 129-136. (in Chinese)

[11] Y Ye, Q Zou, Y Xiao, et al. Effect of interface pretreatment of Al alloy on bonding strength of the laser joined AI/CFRTP butt joint. Micromachines, 2021, 12(2): 179.

[12] Z Zhang, J Shan, X Tan, et al. Improvement of the laser joining of CFRP and aluminum via laser pre-treatment. International Journal of Advanced Manufacturing Technology, 2016, 90: 3465-3472.

[13] T Okada, S Uchida, K Nakata. Effect of Anodizing on direct joining property of aluminum alloy and plastic sheets by friction lap joining. Journal of Light Metal Welding, 2015, 53(8): 298-306.

[14] J Peng. Friction stir welding technology of ABS and aluminum alloy. Lanzhou: Lanzhou University of Technology, 2016. (in Chinese)

[15] Y Ai, K Zheng, Y C Shin, et al. Analysis of weld geometry and liquid flow in laser transmission welding between polyethylene terephthalate (PET) and $\mathrm{Ti}_{6} \mathrm{Al}_{4} \mathrm{~V}$ based on numerical simulation. Optics \& Laser Technology, 2018, 103: 99-108.

[16] H Z Zheng. Study on welding process of dissimilar materials 304 stainless steel and polythylene terephthalate. Zhenjiang: Jiangsu University, 2017. (in Chinese)

[17] W F Cui. Research on the influence of surface texture on the properties of different materials welding joints. Changchun: Changchun University of Science and Technology, 2020. (in Chinese)

[18] M Wahba, Y Kawahito, S Katayama. Laser direct joining of AZ91D thixomolded Mg alloy and amorphous polyethylene terephthalate. Journal of Materials Processing Technology, 2011, 211(6): 1166-1174.

[19] M Grujicic, V Sellappan, M A Omar, et al. An overview of the polymer-tometal direct-adhesion hybrid technologies for load-bearing automotive components. Journal of Materials Processing Tech., 2008, 197(1-3): 363.

[20] A Heckert, M F Zaeh. Laser surface pre-treatment of aluminium for hybrid joints with glass fibre reinforced thermoplastics. Physics Procedia, 2014, 56: 1171-1181.

[21] KW Jung, Y Kawahito, M Takahashi, et al. Laser direct joining of carbon fiber reinforced plastic to zinc-coated steel. Materials \& Design, 2013, 47(5): 179-188.
[22] KW Jung, Y Kawahito, M Takahashi, et al. Laser direct joining of carbon fiber reinforced plastic to aluminum alloy. Journal of Laser Applications, 2013, 25(3): 530-533

[23] A Roesner, S Scheik, A Olowinsky, et al. Laser assisted joining of plastic metal hybrids. Physics Procedia, 2011, 12(1): 370-377.

[24] A Roesner, A Olowinsky4, A Gillner. Long term stability of laser joined plastic metal parts. Physics Procedia, 2013, 41: 169-171.

[25]. E Rodríguez-Vidal, C Sanz, C Soriano, et al. Effect of metal micro-structuring on the mechanical behavior of polymer-metal laser T-joints. Journal of Materials Processing Technology, 2016, 229: 668-677.

[26] J Liu, W F Cui, Y Shi, et al. Effect of surface texture on properties of $316 \mathrm{~L}$ stainless steel and PET dissimilar welded joints. Journal of Manufacturing Processes, 2020, 50: 430-439.

[27] Z Li. Study on ultrasonic assisted laser spot welding mechanism of heterogeneous materials. Changchun: Changchun University of science and technology, 2019. (in Chinese)

[28] H J Zhao. Preparation and tribology of anodic oxidation film on the surface of 7075 aluminum alloy. Qingdao: Qingdao University of technology, 2018. (in Chinese)

[29] Y D She. Study on resistance spot welding joint forming and electrode failure of 5083 aluminum alloy. Shijiazhuang: Hebei University of Science and Technology, 2019. (in Chinese)

[30] W Q Dong. Effect of laser cleaning anodized film of 5083 aluminum alloy on laser welding quality. Wuhan: Hubei University of Technology, 2018. (in Chinese)

[31] X C Ren. Study on microstructure and properties of friction stir welding joint of aluminum alloy and thermoplastic. Welding Technology, 2019, 48(03): 21-25. (in Chinese)

[32] S Q Zhang. Numerical simulation of welding temperature field and stress strain field of T-joint Welding based on SYSWELD. Wuhu: Anhui Polytechnic University, 2011. (in Chinese)

[33] E David, A Lazar. Adhesive bonding between aluminum and polytetrafluoroethylene. Journal of Materials Processing Technology, 2003, 143-144: 191-194

[34] H G Li, J X Bi, W J Ma, et al. Influence of laser roughing technology on microstructure and properties of $\mathrm{C}_{-} \mathrm{f} / \mathrm{SiC}-\mathrm{TC} 4$ brazing joints. Aerospace Materials \& Technology, 2017, 47(01): 42-46. (in Chinese)

[35] Y N Peng, F Mo, CW Mao. Effect of metal surface treatment on the bonding strength between metal and polymer material. Engineering Plastics Application, 2018, 46(01): 45-48. (in Chinese)

\section{Submit your manuscript to a SpringerOpen ${ }^{\circ}$ journal and benefit from:}

- Convenient online submission

- Rigorous peer review

- Open access: articles freely available online

- High visibility within the field

Retaining the copyright to your article

Submit your next manuscript at springeropen.com 